Marquette University

e-Publications@Marquette

\title{
A Comparison of Sexual Minority Youth Who Attend Religiously Affiliated Schools and Their Nonreligious-School-Attending Counterparts
}

\author{
Brandon T. Stewart \\ University of Montana - Missoula \\ Nicholas C. Heck \\ Marquette University, nicholas.heck@marquette.edu \\ Bryan N. Cochran \\ University of Montana - Missoula
}

Follow this and additional works at: https://epublications.marquette.edu/psych_fac

Part of the Psychology Commons

\section{Recommended Citation}

Stewart, Brandon T.; Heck, Nicholas C.; and Cochran, Bryan N., "A Comparison of Sexual Minority Youth Who Attend Religiously Affiliated Schools and Their Nonreligious-School-Attending Counterparts" (2015). Psychology Faculty Research and Publications. 170.

https://epublications.marquette.edu/psych_fac/170 
Marquette University

e-Publications@Marquette

\title{
Psychology Faculty Research and Publications/College of Arts and Sciences
}

This paper is NOT THE PUBLISHED VERSION; but the author's final, peer-reviewed manuscript. The published version may be accessed by following the link in the citation below.

Journal of LGBT Youth, Vol. 12, No. 2 (April 2015): 170-188. DOI. This article is (C) Taylor \& Francis and permission has been granted for this version to appear in e-Publications@Marquette. Taylor \& Francis does not grant permission for this article to be further copied/distributed or hosted elsewhere without the express permission from Taylor \& Francis.

\section{A Comparison of Sexual Minority Youth Who Attend Religiously Affiliated Schools and Their Nonreligious-School-Attending Counterparts.}

\author{
Brandon T. Stewart \\ Department of Psychology, University of Montana, Missoula, Montana \\ Nicholas C. Heck \\ Department of Psychiatry and Human Behavior, Warren Alpert Medical School of Brown University, \\ Providence, Rhode Island \\ Department of Psychology, University of Montana, Missoula, Montana
}

Bryan N. Cochran

Department of Psychology, University of Montana, Missoula, Montana

\section{Abstract}

Sexual minority youth are an at-risk group for negative health outcomes. The present study compares descriptive characteristics and outness of sexual minority youth who attend religious schools to sexual minorities who do not attend religious schools, and also investigates if attending religiously affiliated schools is associated with levels of alcohol use and school belonging among sexual minority youth. Results indicated that 
sexual minority youth attending religiously affiliated schools reported more alcohol-related problems and were less likely to be "out" to students and teachers at their schools when compared to their nonreligious-schoolattending counterparts. Attendance at a religiously affiliated school was not associated with school belonging.

\section{Keywords}

LGBT youth; religious schools; sexual minority youth; Alcohol

Sexual minority youth evidence a heightened risk for experiencing negative mental health outcomes, diminished psychosocial well-being, and more alcohol use than their heterosexual peers (Cochran, Sullivan, \& Mays, 2003; Institute of Medicine, 2011; Kertzner, Meyer, Frost, \& Stirratt, 2009; Kuyper \& Fokkema, [23]; Talley, Sher, Steinley, Wood, \& Littlefield, 2012). Notably, sexual minority youth are at increased risk for overall substance use (Marshall, Friedman, Stall, King, \& Miles, 2008) and past-year prevalence of drug use (Corliss, Rosario, Wypij, Wylie, \& Frazier, 2010) when compared to heterosexual youth. Although religiosity is often viewed as a protective factor that reduces risk for negative health outcomes, research indicates that this phenomenon may not generalize to sexual minorities (Rostosky, Danner, \& Riggle, 2007, 2008, 2010). Furthermore, relative to peers attending private high schools without religious affiliations, sexual minority youth attending private high schools with religious affiliations tend to experience higher levels of minority stressors within the school environment, which in turn may predispose these youth to experience greater problems in terms of mental health and substance use outcomes (Kosciw, Greytak, Bartkiewicz, Boesen, \& Palmer, 2012).

Given the health disparities between sexual minority and heterosexual youth, the objectives of the present study were to investigate whether attending a religiously affiliated school buffers or exacerbate these health disparities for sexual minority youth. Specifically, this study compares descriptive characteristics, outness, feelings of school belonging, and alcohol use among sexual minority youth who attend religiously affiliated schools and youth who attend schools without a religious affiliation.

\section{CONCEPTUAL FRAMEWORK}

Disparities between sexual minority and heterosexual individuals regarding mental health and substance use are hypothesized to be due to what Meyer ([29]) refers to as minority stress. This term illustrates the psychological distress associated with being a sexual minority due to elevated prejudice, discrimination, stigmatization, and general awareness of the negative social attitudes held toward minority populations (Meyer, [28]). The minority stress model, as proposed by Meyer ([28], 2003), relates generally to all populations that are stigmatized due to their minority positions. However, Meyer proposes minority stress processes specific to lesbian, gay, and bisexual (LGB) populations as well. In this LGB-specific framework, Meyer ([29]) makes a distal-proximal distinction due to stress processes that occur both internally and externally for sexual minorities.

The distal (external) component describes objective stress events or circumstances. These events or circumstances can include general stressors (e.g., stress at work, from family), minority status (sexual minority), and prejudice events (discrimination, violence) that can take place in the lives of sexual minorities. The proximal (internal) component consists of the more subjective internalization of sexual minority self-identity. Proximal stress processes entail expectations of rejection, which may cause sexual minorities to be vigilant in social interaction, conceal their identities to avoid harm, and internalize homophobia, where sexual minorities adopt the homophobic beliefs prevalent in general society (Meyer, [29]).

The minority stress model articulated by Meyer describes not only stress processes that are risk factors for disorder but also ameliorative coping processes for the elevated stress experienced by sexual minorities. According to the minority stress model, affiliation opportunities, social support, and coping can serve moderating roles between the impact of stress and mental health outcomes. Personal-level and group-level 
coping processes are distinguished by Meyer to provide a more holistic understanding of the ameliorative techniques sexual minorities may utilize in response to stress. Group-level resources, also conceptualized as minority coping, are thought to delineate boundaries for the limits of individualized coping processes. One such minority coping resource could potentially be affiliation with religious groups (Meyer, [29]).

Religion and spirituality could serve as both personal-level and minority coping resources, due to spirituality being thought of more as personal, internalized, and subjective expressions of the sacred, and religion being thought of more as outward, communal, and institutional expressions (Cotton, Zebracki, Rosenthal, Tsevant, \& Drotar, 2006; Halkitis et al., [11]; Hill \& Pargament, [16]; Zinnbauer et al., [48]). Although there is no consensus on the definition of these terms, research differentiates them into separate expressions of the sacred (Cotton et al., [ 6]; Halkitis et al., [11]; Zinnbauer et al., [48]). Still, there is thought to be considerable overlap between the two constructs (Halkitis et al., [11]; Zinnbauer et al., [48]). The religion component, also known as religiosity, is defined by the level of engagement in religious beliefs, religious service attendance, and frequency of prayer and practice (Cotton et al., [ 6]; Rostosky et al., [34]). Religiosity has become a well-documented significant protective factor against a variety of health risk behaviors for general adolescent populations, including alcohol use, cigarette use, marijuana use, sexual behavior, and behaviors associated with increased morbidity, such as drinking and driving, fighting, and carrying weapons (Cotton et al., [ 6]; Nonnemaker, McNeely, \& Blum, 2003; Wallace, Brown, Bachman, \& Laveist, 2003; Wallace \& Forman, [45]; Wallace et al., [46]).

\section{RELIGIOSITY AMONG SEXUAL MINORITIES}

Studies investigating religiosity among sexual minorities and how it affects substance use are somewhat sparse; however, a growing body of research demonstrates that religiosity is not a protective factor against sexual minority substance use. Specifically, religiosity does not provide protection from alcohol abuse in sexual minority youth (Rostosky et al., [35]), heavy episodic drinking in gay and lesbian young adults (Rostosky et al., [36]), or substance use (binge drinking, smoking, marijuana use) in sexual minority young adults (Rostosky et al., [34]). Other studies highlight the conflict that religion can evoke within sexual minorities, which may help explain why religiosity does not seem to shield them from the effects of stress. For example, Halkitis and colleagues (2009) investigated the meanings and manifestations of religion and spirituality among lesbian, gay, bisexual, and transgender (LGBT) adults and reported that many participants believe that religion has been used as a means to justify exclusion of LGBT individuals.

Consistent with this research, other studies emphasize the social vulnerability for sexual minorities within religious environments (Shilo \& Savaya, [38]). One such study by Dahl ([ 7]) reveals a tendency for sexual minorities to "disidentify" with religion and report sexual and religious identity conflict (p. 90). In addition, a study by Hatzenbuehler, Pachankis, and Wolff (2012) shows that sexual minorities who are in close proximity to religious climates that are "less supportive" of sexual minorities have higher levels of alcohol abuse symptoms and have more sexual partners, even after adjusting for potential confounds at the individual and community levels (p. 660). This study concludes that the religious climate surrounding LGB youth might be a determinant of their health risk behaviors (Hatzenbuehler et al., [12]). According to Rosario, Yali, Hunter, and Gwadz (2006), one might predict that religion would be a risk factor for negative physical and psychological health among LGBT individuals, due to condemnation of same-sex behavior by many religious groups.

The cumulative findings of research exploring religiosity among sexual minorities serve as a caution against overgeneralization of the protective qualities religiosity provides for heterosexual individuals and also indicate that more investigations of religiosity among sexual minorities in differing contexts are needed (Rostosky et al., [34], 2008, 2010). One such context would be the school environment. Only recently have researchers examined the effects of religiosity among sexual minorities within the school setting. Nevertheless, this area is not completely devoid of empirical studies. For example, a study conducted by Gottfried and Polikoff ([10]) is the 
first study to account for the effects of religiosity in the context of sexual minority students' scholastic accomplishment. The authors conclude that sexual minority academic success is unrelated to the religiosity of their environments. In their discussion, they posit that future studies in this area should be expanded to explore the relationship between religiosity and nonacademic outcomes.

Some research explores religiosity among sexual minority youth who attend high school (Gottfried \& Polikoff, [10]; Rostosky et al., [34], 2008, 2010), but those beliefs and practices are not necessarily idealized by the school and are more individual. These studies also do not investigate the characteristics of sexual minorities attending a religiously affiliated school. A thorough research base examining sexual minority youth who attend schools with religious affiliation is lacking in the literature. However, there are some studies that attempt to address this gap. These studies range from investigations of sexual minority youth who attend schools with specific religious identities to broad data on school climates that include sexual minorities who attend religious schools.

\section{SEXUAL MINORITIES WHO ATTEND RELIGIOUSLY AFFILIATED SCHOOLS}

Research on sexual minorities who attend schools with a religious affiliation seems to demonstrate similar results with research involving religiosity among sexual minorities, with sexual and religious identity conflicts being a recurring theme. For example, a study by Maher ([25]) shows that religion and spirituality can be sources of conflict among gay and lesbian students who attend Catholic schools. In addition, almost all of the students who participated in this study witnessed victimization (harassment or violence) against other students who were gay, which had a profound effect on them (Maher, [25]). Attendance at Catholic schools can also create difficulties in the coming-out process for gay and lesbian individuals (Maher \& Sever, [26]; Toman, [41]). For instance, some males who attend Catholic schools may feel pressure to engage in opposite-sex sexual behavior to avoid being labeled as gay (DiGiacomo, [ 8]). Maher and Sever ([26]) argue that Catholic identity creates barriers to addressing gay and lesbian issues in school, including a lack of administrative support in school for fear of community reaction.

More broadly, data from the 2009 and 2011 National School Climate Surveys (Kosciw et al., [21]; Kosciw, Greytak, Diaz, \& Bartkiewicz, 2010) indicate that sexual minority youth in nonreligious private schools have the most favorable school experiences relative to peers in public schools and those in private schools with religious affiliations. Specifically, sexual minority youth attending religiously affiliated schools were more likely to face verbal harassment based on their sexual orientation but did not differ significantly on other types of victimization; they were also less likely to have school supports, such as gay-straight alliances (GSAs), support staff, and supportive administrators (Kosciw et al., [21]).

It is unknown how attending a religiously affiliated school may relate to alcohol use and school belonging in this at-risk population. When there are resources in school that provide support and affiliation opportunities for sexual minority youth, such as inclusion in a GSA, sexual minority youth evidence decreased alcohol use and elevated scores of school belonging and psychosocial well-being (Heck, Flentje, \& Cochran, 2011; Toomey, Ryan, Diaz, \& Russel, 2011). Highly religious contexts demonstrate protective effects on binge drinking and marijuana use among general adolescent populations (Wallace et al., [46]), but it is yet unknown if a highly religious context, such as a religiously affiliated school, can provide such protection for sexual minority youth.

\section{OBJECTIVES AND HYPOTHESES}

The objectives of this study were twofold. For the first objective, an exploration into the characteristics of sexual minority youth who attend religiously affiliated schools was conducted to compare descriptive characteristics of these youth to sexual minority youth who attend schools without a religious affiliation. In addition, this study examined whether attending a religiously affiliated school is associated with being open or "out" about one's sexual orientation to teachers and students at one's high school. The second objective of this study was to 
compare alcohol use and school belonging scores among sexual minorities who attend religiously affiliated schools to sexual minority youth who attend nonreligious schools.

For the first objective, it was anticipated that LGB youth who attend religiously affiliated schools would be less likely to be out than LGB youth who attend schools without religious affiliation. For the second objective, it was hypothesized that attending a religiously affiliated school would have an effect on alcohol use and school belonging for sexual minority youth, though a specific direction of this effect was not predicted, based on the exploratory nature of this study and potentially contradictory findings in the extant literature. Specifically, if youth at religiously affiliated schools are less likely to be out, as we predicted, this could reflect greater efforts to conceal minority status, which may indicate that youth at religiously affiliated schools experience this minority stressor to a greater extent than peers at schools without a religious affiliation. In turn, we would expect youth at schools with religious affiliations to report greater alcohol use and lower levels of school belonging. However, if attending a school with a religious affiliation offers youth a buffer against minority stress, then we would expect that alcohol use and school belonging might be lower and higher, respectively, among youth attending schools with a religious affiliation.

\section{METHOD}

\section{Participants}

The participants included in this study for the first objective were 475 individuals who completed an online survey investigating factors associated with sexual minority mental health and substance use outcomes. Inclusion criteria for this study were that participants identify with a sexual minority orientation (e.g., lesbian, gay, bisexual, queer, questioning) or minority gender identity (such as transgender or transsexual). Second, participants needed to be between ages 16 and 20 and currently attending a public or private high school in the United States. In the United States, public schools are primarily funded by local, state, and government funding, while private schools are usually funded through tuition payments and other sources, such as religious organizations, grants, and charitable donations (U.S. Department of Education, National Center for Education Statistics, 1997).

Heterosexual individuals were eligible to participate in the study if they reported histories that were positive for same-sex sexual behavior or attraction. Considering that sexual identity can fluctuate over time and is only one aspect of sexual orientation, individuals in the sample who had a history of same-sex sexual behavior were included regardless of current identity. For the second objective, a subset of the 475 participants (25 participants from religiously affiliated schools) was matched with their counterparts from non-religiously affiliated schools on the basis of age and gender, resulting in a sample size of 50 participants. This study took place in the United States, and the recruitment processes yielded a sample that was national in scope.

\section{Procedure}

\section{Recruitment}

Researchers identified and contacted groups connected with sexual minority youth, provided general information about the study, and specified incentives for participation. The research team recruited participants from high school GSAs, social networking groups that might be of interest to LGBT youth, LGBT community centers, chapters of the organization Parents, Families, and Friends of Lesbians and Gays (PFLAG), and college/university LGBT student groups and student centers. Research team members reviewed the websites of state-level organizations that advocate on behalf of sexual minority youth and obtained listings of high schools with GSAs. Listings of this kind were obtained for 12 states, and the GSA contact information varied depending on the state (e.g., for some GSAs, only the name and address of the school was provided; in other cases more detailed information, including the advisor's name, was provided). Next, research assistants searched social 
networking site Facebook in an effort to find a Facebook page for each GSA that was listed. Once a Facebook page was located, the research team posted the recruitment message on the wall of the Facebook page. If a Facebook page could not be located or if the recruitment message could not be posted on the Facebook page, then the researchers mailed the recruitment materials directly to the school.

In addition, the research team searched Facebook using 43 search terms (e.g., "gay youth," "GSA," "LGBT," "transgender youth") in an effort to locate additional GSAs and other social networking groups that might be of interest to sexual minority youth. If a group was located, the research team posted the recruitment message on the wall of the group. If unable to post on the wall of the group and a physical mailing address was available, the researchers mailed the recruitment materials to the physical address that was listed. A similar process was used to recruit participants from LGBT community centers, PFLAG chapters, and LGBT college/university groups and centers. Our rationale for recruiting from the latter source was due to the potential for some of these groups and centers to be attended by youth who met the inclusion criteria. Such youth may seek out such groups for socialization, especially if they lack such opportunities within their schools.

\section{Online survey}

Participants could reach the online survey by entering the hyperlink into an Internet browser or by clicking on provided links posted online. Before taking the survey, participants read a consent form and gave electronic consent by agreeing to participate in the study. As an incentive to complete a brief five-item questionnaire to ensure participants met the inclusion criteria, potential participants could enter their e-mail address into a raffle to win a \$10 gift card. Those who met the inclusion criteria were able to enter into a second raffle to win a \$20 gift card. In addition to the items/measures specified in the following section, the online survey was also used to assess age of substance use initiation, childhood abuse, frequency of alcohol and drug use, drug problems and lifetime history of drug use, GSA activities/functioning, LGBT-specific community resources, mental health outcomes, outness, peer/teacher support, school/community climate for LGBT people, school-based victimization, and sensation-seeking levels. These items and measures were administered as part of the survey but were not intended to be analyzed for the purposes of the present study.

\section{Measurement and Instrumentation}

\section{Demographics}

A standard demographics questionnaire included questions about participant age, gender, ethnicity/race, population, relationship status, state of residence, and sexual orientation. Participants selected from a variety of options to describe their sexual orientation (e.g., gay or lesbian, bisexual, straight or heterosexual, unsure, or other). Participants also rated their sexual orientation on a continuous scale (from $1=$ Heterosexual/Straight, to $5=$ Bisexual, to $9=$ Gay/Lesbian). In addition, participants completed items about their sexual history and attraction.

\section{Outness}

Whether or not participants were out in high school was assessed by respondents answering the following question: "Do you consider yourself to be [out] to students and teachers at your high school?" The response options were Yes, No, and Does not apply. The latter classification was included to give heterosexual-identified youth an option for responding.

\section{Religious affiliation and high school characteristics}

Participants selected one of the following options to describe the context of their school: Public school; Private, coed school (i.e., private but males and females both attend); Private, all-boys school; or Private, all-girls school. If a participant selected one of the private school options, a follow-up prompt inquired whether the school had a religious affiliation with Yes/No response options. Participants also responded to an item that asked whether 
their high school had a GSA or student group for LGBT youth and their allies and provided Yes/No response options.

\section{School belonging}

School belonging was quantified with a five-item school connectedness scale articulated by Waters and Cross ([47]) that was slightly adjusted for administration of the measure outside the school setting. The items measured school connectedness by utilizing a five-point Likert scale ( $1=$ Strongly disagree and $5=$ Strongly agree). Sample items from this scale follow: "I feel like I am a part of my high school"; "I feel safe at my high school." The scale was adapted from the Add Health Study (Sieving et al., [39]) and has demonstrated acceptable reliability and validity in previous studies (Waters \& Cross, [47]).

\section{Alcohol use}

The Alcohol Use Disorders Identification Test (AUDIT; Saunders, Aasland, Babor, de la Fuente, \& Grant, 1993) was employed to assess harmful and hazardous alcohol consumption. The ten-item questionnaire in the AUDIT encompasses measurement of alcohol consumption, drinking behavior, and alcohol-related problems. Responses to items are scored on a scale from 0 to 4, with the maximum score being 40. Higher scores on the measure indicate elevated, harmful, and hazardous alcohol consumption (Saunders et al., [37]). A study by Allen, Litten, Fertig, and Babor (1997) reviewing the research on the AUDIT indicates that it has high internal consistency, suggesting that the target construct is measured in a reliable manner.

\section{Data Analysis}

For the first objective, descriptive characteristics were examined for the 25 participants who attended a religiously affiliated school and the other 450 participants in the sample. Using SPSS software, data on demographic information and means were computed and analyzed to explore the descriptive characteristics of sexual minority youth who attend religiously affiliated schools and contrast with sexual minority youth who attend nonreligious schools. Specific descriptive characteristics included for comparison were gender, age, ethnicity/race, relationship status, population of high school town or city, and sexual orientation. To test the hypothesis of the first objective, the differences in outness between groups were tested using chi-square analysis.

To test the hypotheses of the second objective, 25 sexual minorities who attend religiously affiliated schools were matched by age and gender with 25 sexual minorities who do not attend religiously affiliated schools. Participant matching occurred based on these two factors because they are known to be correlated with alcohol misuse (Hawkins et al., [13]; Johnston, O'Malley, \& Bachman, 1992; Robins, [32]). When matching participants in SPSS, participants who did not share the same age and gender identity of a given participant from a religiously affiliated school were first filtered out by selection of cases. A random sample of the remaining participants was then selected to each participant needed with the same age and gender. This process was repeated until all 25 individuals who attend religiously affiliated schools were matched with 25 nonreligious school-attending counterparts. After participant matching, the means of school belonging and AUDIT scores were computed. These means were compared using two independent samples $t$ tests to investigate whether the differences between means were statistically significant.

\section{RESULTS}

Table 1 provides basic demographic data for all participants in this study. Table 2 presents the demographic data for the two groups identified in the second objective. Last, Table 3 offers the comparisons for outness, AUDIT scores, and school belonging scores between the two groups. When sexual orientation was measured on the continuous scale (from $1=$ Heterosexual/Straight, to $5=$ Bisexual, to $9=$ Gay/Lesbian) for all of the participants in the study, the mean score was 6.26 . 
Table 1 General Participant Characteristics

\begin{tabular}{|l|l|l|l|}
\hline & Entire Sample (N = 475) & & Entire Sample (N = 475) \\
\hline Variable & $\mathrm{n}(\%)$ & Variable & $\mathrm{n}(\%)$ \\
\hline Gender & & Relationship status & \\
\hline Male & $179(37.7)$ & Single & $313(65.9)$ \\
\hline Female & $257(54.1)$ & Committed & $104(21.9)$ \\
\hline Transgender & $24(5.0)$ & Dating & $56(11.8)$ \\
\hline Other & $15(3.2)$ & Married & $2(0.4)$ \\
\hline Age & & Population & \\
\hline 16 & $193(40.8)$ & Less than 2,500 & $45(9.5)$ \\
\hline 17 & $198(41.9)$ & $2,500-4,999$ & $62(13.2)$ \\
\hline 18 & $72(15.2)$ & $5,000-9,999$ & $46(9.8)$ \\
\hline 19 & $10(2.1)$ & $10,000-49,999$ & $137(29.0)$ \\
\hline Ethnicity & & $50,000-250,000$ & $105(22.2)$ \\
\hline Caucasian & $329(69.2)$ & More than 250,000 & $77(16.3)$ \\
\hline Hispanic/Chicano & $51(10.7)$ & Religious School & \\
\hline African American & $36(7.6)$ & Yes & $25(5.3)$ \\
\hline Native American & $17(3.6)$ & No & $450(94.7)$ \\
\hline Asian American & $16(3.4)$ & Education level (grade) & \\
\hline Other & $26(5.5)$ & Freshman (9th) & $9(1.9)$ \\
\hline Sexual orientation & & Sophomore (10th) & $93(19.6)$ \\
\hline Gay or lesbian & $213(44.8)$ & Junior (11th) & $171(36.0)$ \\
\hline Bisexual & $132(27.8)$ & Senior (12th) & $202(42.5)$ \\
\hline Straight & $40(8.4)$ & Mean, SD & \\
\hline Unsure & $34(7.2)$ & Age & $16.79,0.76$ \\
\hline Queer & $32(6.7)$ & & \\
\hline Other & $24(5.1)$ & & \\
\hline Note. Two participants & nad & & \\
\hline
\end{tabular}

Note. Two participants had missing data for age and three participants had missing data for the population of their high school city or town.

Table 2 Demographic Characteristics of Youth From Religiously Affiliated and Nonreligious High Schools ( $N=25$ for Each Sample)

\begin{tabular}{|l|l|l|l|}
\hline Variable & $\begin{array}{l}\text { Religiously Affiliated\% } \\
\text { (Nonreligious\%) }\end{array}$ & Variable & $\begin{array}{l}\text { Religiously Affiliated\% } \\
\text { (Nonreligious\%) }\end{array}$ \\
\hline Ethnicity & & Relationship status & \\
\hline Caucasian & $52.0(70.2)$ & Single & $72.0(65.6)$ \\
\hline Hispanic/Chicano & $20.0(10.2)$ & Committed & $12.0(22.4)$ \\
\hline $\begin{array}{c}\text { African } \\
\text { American }\end{array}$ & $16.0(7.1)$ & Dating & $12.0(11.8)$ \\
\hline Native American & $0.0(3.8)$ & Married & $4.0(0.2)$ \\
\hline Asian American & $8.0(3.1)$ & Population & \\
\hline Other & $4.0(5.6)$ & Less than 2,500 & $12.6(9.4)$ \\
\hline Sexual orientation & & $2,500-4,999$ & $8.3(13.4)$ \\
\hline Gay or lesbian & $28.0(45.8)$ & $5,000-9,999$ & $0.0(10.3)$ \\
\hline Bisexual & $44.0(26.9)$ & $10,000-49,999$ & $8.3(30.1)$ \\
\hline Straight & $16.0(8.0)$ & $50,000-250,000$ & $25.0(22.1)$ \\
\hline
\end{tabular}




\begin{tabular}{|l|l|l|l|}
\hline Unsure & $8.0(7.1)$ & $\begin{array}{c}\text { More than } \\
250,000\end{array}$ & $45.8(14.7)$ \\
\hline Queer & $4.0(6.9)$ & High school GSA & \\
\hline Other & $0.0(5.3)$ & Yes & $52.0(80.0)$ \\
\hline & & No & $48.0(20.0)$ \\
\hline
\end{tabular}

Note. Three participants had missing data for the population of the city or town of high school attendance (one participant from religiously affiliated schools and two participants from nonreligious schools).

Table 3 Comparison of Outness Levels, AUDIT Scores, and School Belonging Scores

\begin{tabular}{|l|l|l|l|}
\hline Comparison & Religiously Affiliated\% (Nonreligious\%) & $\chi^{2}(\mathrm{df}=1)$ & $\mathrm{p}$ Value (two-tailed) \\
\hline Out in high school? & & & \\
\hline Yes & $33.3(67.0)$ & 9.990 & $0.002^{* *}$ \\
\hline No & $66.7(33.0)$ & & \\
\hline & M score (SD) & $\mathrm{t}(\mathrm{df})$ & \\
\hline AUDIT scores & & & \\
\hline Religiously affiliated & $7.76(10.08)$ & $2.46(34.22)$ & $0.019^{*}$ \\
\hline Nonreligious & $2.28(4.77)$ & & \\
\hline School belonging & & & \\
\hline Religiously affiliated & $18.52(6.09)$ & $1.31(48)$ & 0.195 \\
\hline Nonreligious & $16.52(4.57)$ & & \\
\hline$p<.05 ; * * p<.01$ & & & \\
\hline
\end{tabular}

${ }^{*} p<.05 ;{ }^{* *} p<.01$

The first objective explored the demographics of sexual minorities who attended religiously affiliated schools. Relative to sexual minorities attending nonreligious schools, sexual minorities who attended schools with a religious affiliation tended to attend high school in more densely populated areas. The religiously affiliated group was also more heterogeneous concerning ethnicity, had a higher proportion of bisexual individuals, and had fewer gay and lesbian individuals than the nonreligious group (refer to Table 2 for percentages). Although $33.3 \%(n=7)$ of participants from religiously affiliated schools were out to students and teachers at their high schools, $67.0 \%$ of participants $(n=272)$ from nonreligious schools were out. A chi-square analysis indicated a significant difference between these two groups, $\chi^{2}(d f=1)=9.990, p=0.002$ (two tailed).

For the second objective, scores on the AUDIT assessed alcohol problems. Sexual minorities attending religiously affiliated schools reported higher AUDIT scores $(M=7.76, S D=10.08)$ when compared to the matched sample of sexual minorities attending nonreligious schools $(M=2.28, S D=4.77)$. This difference between mean scores (with equal variances not assumed) was statistically significant ( $t=2.46, d f=34.22, p=0.019$, two tailed). School belonging was quantified with the modified school connectedness scale, with higher scores indicating higher levels of school belonging. The mean score for school belonging was slightly higher for sexual minorities who attended religiously affiliated schools $(M=18.52, S D=6.09)$ than their matched counterparts at nonreligious schools ( $M=16.52, S D=4.57$ ); however, this difference between school belonging mean scores (with equal variances assumed) was not statistically significant ( $t=1.31, d f=48, p=0.195$, two tailed).

\section{DISCUSSION}

Research studies of sexual minorities who attend religiously affiliated schools are few in the extant literature. Investigations into both protective factors, which can help buffer the health disparities between sexual minorities and heterosexuals, and risk factors, which may contribute to these negative outcomes, are necessary. This study explored whether attendance at a religiously affiliated school could offer these protective qualities, or if such a climate could be a risk factor adding to the already elevated stress faced by sexual minorities. Attending religiously affiliated schools was not associated with a significant difference in school belonging in comparison to 
attending nonreligious schools. However, attending religiously affiliated schools, for sexual minority youth, was associated with higher levels of alcohol use. In addition, when attending a religious school, sexual minority youth were less likely to be out with their sexual orientation to students and teachers at school when compared to their nonreligious school-attending counterparts.

These results support the hypothesis of the first objective and partially support the hypotheses of the second objective. Attendance at religiously affiliated schools had a significant association with alcohol use, and sexual minorities who attended these schools were less likely to consider themselves as being out to others at their high schools. Despite the fact that attending a religiously affiliated school had no significant association with school belonging, which was contrary to the hypothesis of the second objective, implications can still be made. In the first objective, the results demonstrate that sexual minorities who attend religiously affiliated schools tend to conceal their sexual orientation more than their nonreligious school-attending counterparts. This could potentially be due to the conflict that religion can create for sexual minorities and their identities. Sexual minorities who attend religiously affiliated schools may exhibit the same tendency to "disidentify" with religion and experience sexual and religious identity conflict, as was found in the study by Dahl ([ 7], p. 90).

This conflict may help explain why most of the participants in the sample attended public schools, due to the increased frequency of concealment among sexual minorities who attend religiously affiliated schools. Further, this conflict may also help explain the lower proportion of gay and lesbian individuals within the religiously affiliated group. There was, however, a higher proportion of bisexual individuals within the religiously affiliated group when compared to other sexual minority orientations. These findings are surprising, because research elucidates that those with a bisexual orientation may face more stigma and stressors than those with a gay, lesbian, or heterosexual orientation (Beaber, [ 2]; Bostwick, [ 3]; Eliason, [ 9]; Jorm, Korten, Rodgers, Jacomb, \& Christensen, 2002); thus these individuals may be more likely to conceal their sexual identity. Yet bisexual individuals comprised close to half of the percentage of respondents in the religiously affiliated group. Perhaps this nuance could be attributed to bisexuality being a safer sexual identity to reveal to others in religiously affiliated institutions. If this is the case, then among sexual minority youth who attend religiously affiliated schools, bisexual individuals may be more likely to participate in research where they would be asked questions regarding their sexual orientation.

The combination of higher levels of problematic alcohol use and higher levels of sexual orientation concealment (i.e., low outness levels) supports Meyer's minority stress hypothesis. Concealment of sexual orientation, which is a proximal stressor in the model, can be associated with elevated stress for sexual minorities. An increase in minority stress could potentially result in individuals using alcohol to alleviate this distress (Meyer, [29]; Mulia, Ye, Zemore, \& Greenfield, 2008). This hypothesis may help explain the co-occurring increase in alcohol use and concealment of sexual orientation demonstrated by sexual minorities who attend religiously affiliated schools.

\section{Limitations}

There were several limitations that warrant acknowledgment and limit the generalizability of the results found in this study. The first limitation was the small number of participants who were in the religiously affiliated school attendance group. This small number of participants can reduce the statistical power of the obtained results. However, sampling sexual minority youth from religiously affiliated schools is a challenge in itself, especially because there appears to be a high rate of concealment of sexual orientation among this group. The second limitation was in regard to randomization. Participants were not randomized to schools with religious affiliation or schools without religious affiliation, and therefore causal inferences cannot be made for the relationship among attendance to religiously affiliated schools, the descriptive characteristics, and the dependent variables. 
In addition, a random sample was not compared in the second objective for AUDIT scores and school belonging, but instead a matched sample was compared. Although matching on the basis of key characteristics that are thought to be predictive of alcohol misuse helps to effectively compare mean scores, some selection bias may be present when using only age and gender. Matching on other characteristics that could potentially influence alcohol use (such as ethnicity or population of city or town of high school attendance), in addition to age and gender, would allow for these groups to be compared more effectively. Yet the small number of participants collected who attend religiously affiliated schools restricted access to matching on such characteristics.

A third limitation of the study involves the homogeneity of the sample. The homogeneous nature of the sample limits generalizability to less-represented groups. Although, the religiously affiliated group was more heterogeneous than the matched nonreligious group included in the second objective because it had more representation from groups other than Caucasian ethnic identity (with the exception of Native American ethnic identity; and the two groups had about the same representation of "other" ethnic identity), the small sample size limits generalizability to other groups. Another limitation is the utilization of convenience sampling methodology. This could potentially restrict the generalizability of the results because self-selection bias may be present and not represent the entire target population. Despite the limitations within this study, a noteworthy strength was also present. The study represents participants recruited nationally and is not limited to just one or several geographic locations. Future research in this area could address the limitations of this study.

\section{Future Directions}

The results of this study indicate that additional research in this area is needed to further delineate the relationship between attending religiously affiliated schools and the associated impacts on sexual minority youth. In the future, research in this area could focus on associated school constituents other than school belonging or outness (such as victimization). Research in this area could investigate what it is about the religious school environment that might confer additional distress and alcohol abuse. In addition, researchers could investigate how attending religiously affiliated schools relates to more general substance use such as marijuana, cocaine, methamphetamine, or other substances. These studies could eliminate some of the limitations of this study by having a larger sample size of participants who attend religiously affiliated schools and compare them to a random sample of sexual minorities who attend nonreligious schools. Future directions of research in this area could also compare how different religious groups or religious denominations within schools (e.g., Catholic schools versus Protestant schools) influence sexual minorities. Investigating whether bisexuality is a safer sexual identification to reveal in religious institutions when compared to gay and lesbian sexual identification could also be a topic of interest.

Future research could be longitudinal rather than cross-sectional and include a more heterogeneous sample, which would allow more definitive conclusions and generalization to a wider range of populations. Additional future research topics could include exploratory studies that are descriptive in nature, such as elucidation of certain characteristics of religiously affiliated schools that necessitate concealment of sexual orientation and alcohol use. For example, Heck, Lindquist, Stewart, Brennan, and Cochran (2013) investigated reasons why sexual minority youth do not join GSAs; they derived themes that were common among sexual minorities who did not join. A similar study could highlight themes regarding what aspects of religiously affiliated schools impact these associated negative outcomes and, in addition, identify themes that are possibly protective against them.

Qualitative studies could also add to this area by providing personal insights into the conflicts that sexual minorities face while attending religious schools and the methods that individuals use to help reconcile sexual and religious identities. For instance, a study by Levy and Reeves ([24]) includes in-depth interviews of gay, lesbian, and queer individuals with a Christian upbringing to understand the process by which these individuals resolve conflicts between their sexual identity and religious beliefs. How such potential conflicts are resolved by 
individuals in a religiously affiliated school environment is an important area for future study. Rosario and colleagues (2006) state that the sexual minorities who are most likely to experience the health benefits of religion are those who integrate their sexual and religious identities.

Studies investigating religion, or religiosity, and sexual minorities demonstrate that it may not be a protective factor among this population. If sexual minority youth who attend religiously affiliated schools are facing increased minority stress above and beyond the health disparities already present within this at-risk population, then future research is needed in this area to document the risks involved with attendance at such schools as a sexual minority. In addition, research can explore aspects of religiously affiliated schools that are risk and protective factors for sexual minority youth. Inclusion of interventions, such as GSAs, may provide support for sexual minority students who attend religiously affiliated schools. Future research in this area will fill a large gap within the literature and better capture the experiences of sexual minorities who attend religiously affiliated schools.

\section{FUNDING}

This research was supported by a grant from the National GLBTQ Youth Foundation awarded to Nicholas C. Heck. The views expressed herein do not necessarily reflect the views of the funding source.

\section{Footnotes}

${ }^{1}$ For the present study, sexual minority youth are defined as those who self-identify as lesbian, gay, bisexual, transgender, or queer, or youth with a history of same-sex attraction or same-sex sexual behavior.

*Present affiliation: Department of Psychology, Marquette University, Milwaukee, Wisconsin, USA

\section{REFERENCES}

Allen, J.P., Litten, R.Z., Fertig, J.B., \& Babor, T. (1997). A review of research on the Alcohol Use Disorders Identification Test (AUDIT). Alcoholism: Clinical and Experimental Research, 21(4), 613-619.

Beaber, T. (2008). Well-being among bisexual females: The role of internalized biphobia, stigma consciousness, social support, and self-disclosure (Doctoral dissertation). Retrieved from ProQuest Information and Learning (4-B69, 2616).

Bostwick, W.B. (2006). Bisexual identity, stigma, and health among college women (Doctoral dissertation). Retrieved from ProQuest Information and Learning (7-B66, 3659).

Cochran, S.D., Sullivan, J.G., \& Mays, V.M. (2003). Prevalence of mental disorders, psychological distress, and mental health services use among lesbian, gay, and bisexual adults in the United States. Journal of Consulting and Clinical Psychology, 71, 53-61.

Corliss, H.L., Rosario, M., Wypij, D., Wylie, S.A., \& Frazier, A.L. (2010). Sexual orientation and drug use in a longitudinal cohort study of U. S. adolescents. Addictive Behaviors, 35(5), 517-521.

Cotton, S., Zebracki, K., Rosenthal, S.L., Tsevant, J., \& Drotar, D. (2006). Religion/spirituality and adolescent health outcomes: A review. Journal of Adolescent Health, 38, 472-480.

Dahl, A. (2010). The religious experience of sexual minority youth: Identity, integration, and minority stress. ProQuest Information and Learning, 70(8-B), 5204.

DiGiacomo, J. (1993). Morality and youth: Fostering Christian identity. Kansas City, MO: Sheed and Ward.

Eliason, M. (2000). Bi-negativity: The stigma facing bisexual men. Journal of Bisexuality, 1(2-3), 137-154.

Gottfried, M.A., \& Polikoff, M.S. (2012). A religious experience? Personal, parental, and peer religiosity and the academic success of sexual-minority youth using nationally representative samples. Journal of LGBT Youth, 9(3), 183-199. 
Halkitis, P.N., Mattis, J.S., Sahadath, J.K., Massie, D., Ladyzhenskaya, L., Pitrelli, K.,. Cowie, S.E. (2009). The meanings and manifestations of religion and spirituality among lesbian, gay, bisexual, and transgender adults. Journal of Adult Development, 16(4), 250-262.

Hatzenbuehler, M.L., Pachankis, J.E., \& Wolff, J. (2012). Religious climate and health risk behaviors in sexual minority youths: A population based study. American Journal of Public Health, 102(4), 657-663.

Hawkins, D.J., Graham, J.W., Maguin, E., Abbott, R., Hill, K.G., \& Catalano, R.F. (1997). Exploring the effects of age alcohol use initiation and psychosocial risk factors on subsequent alcohol misuse. Journal of Studies on Alcohol, 58(3), 280-290.

Heck, N.C., Flentje, A., \& Cochran, B.N. (2011). Offsetting risks: High school gay-straight alliances and lesbian, gay, bisexual, and transgender (LGBT) youth. School Psychology Quarterly, 26(2), 161-174.

Heck, N.C., Lindquist, L.M., Stewart, B.T., Brennan, C., \& Cochran, B.N. (2013). To join or not to join: Gay-straight student alliances and the high school experiences of lesbian, gay, bisexual, and transgender youths. Journal of Gay and Lesbian Social Services, 25(1), 77-101.

Hill, P.C., \& Pargament, K.I. (2003). Advances in the conceptualization and measurement of religion and spirituality: Implications for physical and mental health research. American Psychologist, 58(1), 64-74.

Institute of Medicine. (2011). The health of lesbian, gay, bisexual, and transgender people: Building a foundation for better understanding. Washington, DC: Institute of Medicine.

Johnston, L.D., O'Malley, P.M., and Bachman, J.G. (1992). Smoking, drinking, and illicit drug use among American secondary students, college students, and young adults (Vol. 1, NIH Publication No. 93-3480). Washington, DC: Government Printing Office.

Jorm, A.F., Korten, A.E., Rodgers, B., Jacomb, P.A., \& Christensen, H. (2002). Sexual orientation and mental health: Results from a community survey of young and middle-aged adults. British Journal of Psychiatry, $180,423-427$.

Kertzner, R.M., Meyer, I.H., Frost, D.M., \& Stirratt, M.J. (2009). Social and psychological well-being in lesbians, gay men, and bisexuals: The effects of race, gender, age, and sexual identity. American Journal of Orthopsychiatry, 79(4), 500-510.

Kosciw, J.G., Greytak, E.A., Bartkiewicz, M.J., Boesen, M.J., \& Palmer, N.A. (2012). The 2011 National School Climate Survey: The experiences of lesbian, gay, bisexual, and transgender youth in our nation's schools. New York, NY: GLSEN.

Kosciw, J.G., Greytak, E.A., Diaz, E.M., \& Bartkiewicz, M.J. (2010). The 2009 National School Climate Survey: The experiences of lesbian, gay, bisexual, and transgender youth in our nation's schools. New York, NY: GLSEN.

Kuyper, L., \& Fokkema, T. (2011). Minority stress and mental health among Dutch LGBs: Examination of differences between sex and sexual orientation. Journal of Counseling Psychology, 58(2), 222-233.

Levy, D.L., \& Reeves, P. (2011). Resolving identity conflict: Gay, lesbian, and queer individuals with a Christian upbringing. Journal of Gay and Lesbian Social Services, 23(1), 53-68.

Maher, M.J. (2007). Gay and lesbian students in Catholic high schools: A qualitative study of alumni narratives. Catholic Education: A Journal of Inquiry and Practice, 10(4), 449-472.

Maher, M.J., \& Sever, L.M. (2007). What educators in Catholic schools might expect when addressing gay and lesbian issues: A study of needs and barriers. Journal of Gay and Lesbian Issues in Education, 4(3), 79111.

Marshall, M.P., Friedman, M.S., Stall, R., King, K.M., \& Miles, J. (2008). Sexual orientation and adolescent substance use: A meta-analysis and methodological review. Addiction, 103(4), 546-556.

Meyer, I.H. (1995). Minority stress and mental health in gay men. Journal of Health and Social Behavior, 36, 3856.

Meyer, I.H. (2003). Prejudice, social stress, and mental health in lesbian, gay, and bisexual populations: Conceptual issues and research evidence. Psychological Bulletin, 129, 674-697.

Mulia, N., Ye, Y., Zemore, S.E., \& Greenfield, T.K. (2008). Social disadvantage, stress, and alcohol use among Black, Hispanic, and White Americans: Findings from the 2005 U.S. National Alcohol Survey. Journal of Studies on Alcohol and Drugs, 69(6), 824-833. 
Nonnemaker, J.M., McNeely, C.A., \& Blum, R.M. (2003). Public and private domains of religiosity and adolescent health risk behaviors: Evidence from the National Longitudinal Study of Adolescent Health. Social Science and Medicine, 57(11), 2049-2054.

Robins, L.N. (1992). Synthesis and analysis of longitudinal research on substance abuse. Unpublished report,, Princeton, NJ: Robert Wood Johnson Foundation

Rosario, M., Yali, A.M., Hunter, J., \& Gwadz, M.V. (2006). Religion and health among lesbian, gay, and bisexual youths: An empirical investigation and theoretical explanation. Washington, DC: American Psychological Association.

Rostosky, S.S., Danner, F., \& Riggle, E.D. B. (2007). Is religiosity a protective factor against substance use in young adulthood? Only if you are straight! Journal of Adolescent Health, 40, 440-447.

Rostosky, S.S., Danner, F., \& Riggle, E.D. B. (2008). Religiosity and alcohol use in sexual minority and heterosexual youth and young adults. Journal of Youth and Adolescence, 37(5), 552-563.

Rostosky, S.S., Danner, F., \& Riggle, E.D. B. (2010). Religiosity as a protective factor against heavy episodic drinking (HED) in heterosexual, bisexual, gay, and lesbian young adults. Journal of Homosexuality, 57, 1039-1050.

Saunders, J.B., Aasland, O.G., Babor, T.F., de la Fuente, J.R., \& Grant, M. (1993). Development of the Alcohol Use Disorders Identification Test (AUDIT): WHO collaborative project on early detection of persons with harmful alcohol consumption-II. Addiction, 88, 791-804.

Shilo, G., \& Savaya, R. (2012). Mental health of lesbian, gay, and bisexual youth and young adults: Differential effects of age, gender, religiosity, and sexual orientation. Journal of Research on Adolescence, 22(2), 310-325.

Sieving, R.E., Beuhring, T., Resnick, M.D., Bearinger, L.H., Shew, M., Ireland, M., \& Blum, R.W. (2001). Development of adolescent self-report measures from the National Longitudinal Study of Adolescent Health. Journal of Adolescent Health, 28, 73-81.

Talley, A.E., Sher, K.J., Steinley, D., Wood, P.K., \& Littlefield, A.K. (2012). Patterns of alcohol use and consequences among empirically derived sexual minority subgroups. Journal of Studies on Alcohol and Drugs, 73(2), 290-302.

Toman, J.A. (1997). Dual identity: Being Catholic and being gay. Dissertation Abstracts International, 58(05), 1942A.

Toomey, R., Ryan, C., Diaz, R., \& Russel, S. (2011). High school gay-straight alliances (GSAs) and young adult wellbeing: An examination of GSA presence, participation, and perceived effectiveness. Applied Developmental Science, 15(4), 175-185.

U.S. Department of Education, National Center for Education Statistics. (1997). Public and private schools: How do they differ? (NCES 97-983, No. 12). Washington, DC: National Center for Education Statistics.

Wallace, J.M., Brown, T.N., Bachman, J.G., \& Laveist, T.A. (2003). The influence of race and religion on abstinence from alcohol, cigarettes, and marijuana among adolescents. Journal of Studies on Alcohol, 64(6), 843-848.

Wallace, J.M., \& Forman, T.A. (1998). Religion's role in promoting health and reducing risk among American youth. Health Education and Behavior, 25(6), 721-741.

Wallace, J.M., Yamaguchi, R., Bachman, J.G., O'Malley, P.M., Schulenburg, J.E., \& Lloyd, J.D. (2007). Religiosity and adolescent substance use: The role of individual and contextual influences: Erratum. Social Problems, 54(3), 395-397.

Waters, A., \& Cross, D. (2010). Measuring students' connectedness to school, teachers, and family: Validation of three scales. School Psychology Quarterly, 25, 164-177.

Zinnbauer, B.J., Pargament, K.I., Cole, B., Rye, M.S., Butter, E.M., Belavich, T.G.,. Kadar, J.L. (1997). Religion and spirituality: Unfuzzying the fuzzy. Journal for the Scientific Study of Religion, 36(4), 549-564. 